\title{
Organização do serviço de controle da tuberculose em Distrito Sanitário Especial Indígena Potiguara
}

\author{
The organization of a tuberculosis control service in a Special Potiguara Indigenous Health District
}

Organización del servicio de control de la tuberculosis en Distrito Sanitario Especial Indígena de Potiguara

Rafaela Gerbasi Nóbrega ${ }^{1}$, Jordana de Almeida Nogueira ${ }^{2}$, Lenilde Duarte de Sá3 ${ }^{3}$ Rosa Emília Malta do Nascimento Uchôa4 Débora Raquel Soares Guedes Trigueiro ${ }^{5}$, Rosa Camila Gomes Paiva ${ }^{6}$

\footnotetext{
${ }^{1}$ Enfermeira, Mestre em Enfermagem. Professora do Centro Universitário de João Pessoa. João Pessoa, PB, Brasil. E-mail: rafaelagerbasi@yahoo.com.br.

2 Enfermeira, Doutora em Enfermagem. Professor Adjunto IV da Universidade Federal da Paraíba (UFPB). João Pessoa, PB, Brasil. E-mail: jal nogueira@yahoo.com.br.

${ }^{3}$ Enfermeira, Doutora em Enfermagem. Professor Adjunto IV da UFPB. João Pessoa, PB, Brasil. E-mail: lenilde sa@yahoo.com.br.

${ }^{4}$ Fisioterapeuta. Recife, PE, Brasil. E-mail: milinhamalta@hotmail.com.

${ }^{5}$ Enfermeira, Mestre em Enfermagem. João Pessoa, PB, Brasil. E-mail: deborasgt@hotmail.com.

${ }^{6}$ Enfermeira, Mestre em Enfermagem. Professora do Centro Universitário de João Pessoa. João Pessoa, PB, Brasil. E-mail: rosac12@hotmail.com.
}

\section{RESUMO}

Buscou-se com este trabalho analisar a organização do serviço de controle da tuberculose no Distrito Sanitário Especial Indígena (DSEI) Potiguara, sob a óptica dos profissionais de saúde indígena. Trata-se de estudo de natureza qualitativa, realizado no DSEI Potiguara/Paraíba, reunindo 23 profissionais de saúde. O material empírico foi produzido a partir da técnica de grupo focal e analisado segundo a abordagem crítica da técnica de análise de discurso. Como potencialidades constataram-se disponibilidade de insumos para realização do exame bacteriológico, garantia do fluxo laboratorial e agilidade no recebimento dos resultados. Quanto às fragilidades, evidenciou-se que o modo como o serviço se organiza favorece descontinuidade das ações; fragmentação do cuidado; comunicação deficiente entre os diferentes pontos da atenção. Recomenda-se a adoção de mecanismos de gestão que ultrapasse as barreiras burocráticas e consolide-se em proposta inovadora, coordenada, cuja organização se assente potencialmente nas relações que envolvem pessoas, tecnologia e recursos.

Descritores: Tuberculose; População Indígena; Avaliação de Serviços de Saúde; Enfermagem em Saúde Pública.

\section{ABSTRACT}

The objective was to analyze the organization of the tuberculosis control service in the Special Potiguara Indigenous Health District, from the view of indigenous health workers. This qualitative study was performed at the referred indigenous health district in the state of Paraíba, with 23 health workers. The empirical material was produced based on the foal group technique and analyzed according to the analytic approach of the discourse analysis technique. The identified strengths included the availability of resources for performing the bacteriological examination, guarantee laboratory functioning and timely results. Regarding the weaknesses, it was found that the organization of the service favors an interruption of the actions; fragmentation of care; inefficient communication between the different points of care. It is recommended that management mechanisms be adopted to overcome the bureaucratic barriers and consolidate an innovating and coordinated proposal, whose organization is mainly based on relationships that involve people, technology and resources.

Descriptors: Tuberculosis; Indigenous Population; Health Services Evaluation; Public Health Nursing.

\section{RESUMEN}

Se analizó la organización del servicio de control de tuberculosis en el Distrito Sanitario Especial Indígena (DSEI) Potiguara, bajo la óptica de profesionales de salud indígena. Estudio cualitativo, realizado en DSEI Potiguara-Paraíba, convocando a veintitrés profesionales de salud. El material empírico fue generado según técnica de grupo focal, y analizado mediante abordaje crítico de la técnica de análisis del discurso. Se constataron como potencialidades la disponibilidad de insumos para realización de exámenes bacteriológicos, garantía de disponibilidad laboratorial y agilidad en la recepción de resultados. Respecto a las debilidades, se evidenció que el modo organizativo del servicio favorece la discontinuidad de sus acciones: fragmentación del cuidado, comunicación deficiente entre los diferentes puntos de atención. Se recomienda adoptar mecanismos de gestión que sobrepasen los obstáculos burocráticos y se consoliden en una propuesta innovadora, coordinada, cuya organización se base fundamentalmente en las relaciones que involucran a personas, tecnología y recursos.

Descriptores: Tuberculosis; Población Indígena; Evaluación de Servicios de Salud; Enfermería en Salud Pública. 


\section{INTRODUÇÃO}

No ranking mundial dos 22 países que concentram $80 \%$ dos casos de tuberculose (TB), o Brasil ocupa a $19^{a}$ posição. Em 2010 foram notificados no país 70.601 casos novos da doença, com taxas de incidência de 37,9 e mortalidade de 2,5 casos por 100 mil habitantes ${ }^{(1)}$. Destaca-se que o padrão de distribuição espacial da TB se apresenta de maneira heterogênea nas diferentes regiões geopolíticas, disseminando-se predominantemente entre os grupos que vivem em situação de vulnerabilidade socioeconômica.

Os povos indígenas, caracterizam-se como um grupo em que as chances de se infectar e adoecer por TB é aproximadamente 10 vezes superior, quando comparados à população brasileira(2). Embora não seja conhecida precisamente a situação epidemiológica entre estes povos, estudos mostram taxas de incidência superior a 140 casos para 100.000 habitantes, alcançando em algumas localidades incidência média de 284 casos рага 100.000 habitantes $^{(3-5)}$.

Com exceção dos estados do Rio Grande do Norte e Piauí, os povos indígenas estão presentes em praticamente todo território brasileiro. Estima-se a existência de 538.154 indígenas, representantes de 210 povos, falantes de mais de 170 línguas, residentes em 4.413 aldeias que se localizam em 432 municípios(5). $^{(5)}$

Na Paraíba, a etnia Potiguara, uma das maiores do Brasil, reúne uma população estimada de 14.831 indivíduos, distribuídos em 29 aldeias dos municípios de Baía da Traição, Marcação e Rio Tinto. A organização da rede de serviços de saúde no Distrito Sanitário Especial Indígena (DSEI) Potiguara é articulada com o Sistema Único de Saúde (SUS) e com os municípios locais, desenvolvendo ações previstas no Plano Distrital para o atendimento à assistência básica, incluindo o controle da $\mathrm{TB}^{(6)}$.

Atualmente, a TB é um agravo sob responsabilidade da atenção básica à saúde indígena, definido como prioritário pelo Plano Anual de Trabalho do Departamento de Saúde Indígena (DESAI), conferindo a previsão de recursos orçamentários para a implantação e implementação das atividades de controle da doença. Atribui-se às equipes de saúde indígena, a missão de ampliar o acesso às tecnologias disponíveis para diagnóstico e tratamento da doença. No entanto, a expansão e uso destas tecnologias não se restringem simplesmente a uma abordagem clínica, mas requer uma política que assegure a inserção das ações de controle da TB no sistema de saúde(7).

Parte-se da premissa que a construção sistemática e planejada do cuidado em saúde, requer não apenas a implementação de ações básicas de prevenção e assistência, mas, sobretudo, resulta do fortalecimento e integração entre os diferentes pontos de atenção à saúde existentes no município/região. A integração propriamente dita dos cuidados consiste em uma coordenação das práticas clínicas com a finalidade de assegurar a continuidade e a globalidade do elenco de serviços ofertados em organizações, considerando a densidade tecnológica crescente ${ }^{(8)}$.

Destaca-se, portanto, que a utilização dos serviços por parte da população refere-se à extensão e ao tipo de uso dos serviços de saúde. O reconhecimento de problemas por profissionais de saúde é a etapa que precede o processo diagnóstico, estando estes intrinsecamente ligados a questões estruturais como, por exemplo, a acessibilidade (localização do serviço, horário de funcionamento), variedade de serviços (pacote de serviços disponíveis à comunidade), população eletiva (população pela qual assume responsabilidade) e continuidade (atenção oferecida em uma sucessão ininterrupta de eventos).

Considerando as especificidades que permeiam a lógica de organização para a produção do cuidado às populações indigenas, presume-se que os componentes estruturais sejam assegurados, recursos variados estejam disponíveis, permitindo às equipes de saúde o exercício de suas competências com garantia que o cuidado, iniciado na atenção básica, seja estendido a outros níveis, quando a situação dele não possa prescindir.

Configura-se, portanto, como um importante desafio do processo gerencial conseguir programar adequadamente este conjunto de ações diversificadas, de modo que elas resultem em um cuidado coordenado eficaz e de qualidade ${ }^{(9)}$. No que diz respeito à suspeição, diagnóstico e acompanhamento dos casos de TB exige-se que fundamentalmente sejam assegurados um conjunto de ações, tais como: garantia de insumos para a coleta de baciloscopia, o procedimento de coleta de material deve estar disponibilizado em todas as unidades da atenção básica, condições de armazenamento do material colhido/fluxo e retaguarda laboratorial/acesso a exames 
complementares (RX de tórax, PPD), logística de distribuição de medicamentos, eficiência no fluxo de informações, qualificação e supervisão dos recursos humanos.

Logo, reconhece-se que para promover melhor desempenho das equipes de saúde indígena no manejo dos casos de TB, as ações devem organizar-se e ajustar-se às especificidades locais e, sobretudo, contar como uma rede de apoio articulada que ofereça efetivamente respostas às necessidades identificadas.

Tendo em vista que os índios constituem populações especiais para a implementação das ações de controle da TB, buscou-se analisar a organização do serviço de controle da TB no DSEI Potiguara, sob a óptica dos profissionais de saúde indígena.

\section{MÉTODOS}

Estudo descritivo, de natureza qualitativa, realizado no DSEI Potiguara no estado da Paraíba. O DSEI Potiguara tem como base de organização os serviços de saúde nas aldeias. Cada aldeia/comunidade conta com a atuação do Agente Indígena de Saúde (AIS), cujas atividades estão vinculadas a um posto de saúde. Seguindo o fluxo de organização dos serviços de saúde, essas comunidades contam com outras instâncias de atendimento que são os Pólos-Base, constituindo a primeira referência para os AIS que atuam nas aldeias. Cada Pólo-Base cobre um conjunto de aldeias e sua equipe, e está estruturado como Unidade Básica de Saúde (UBS), com atuação de equipe multidisciplinar.

Participaram do estudo 23 profissionais de saúde entre médicos, enfermeiros, técnicos de enfermagem e AIS, pertencentes a três equipes de saúde dos municípios de Rio Tinto, Marcação e Baía da Traição. A seleção destes profissionais atendeu às recomendações e conveniência das coordenações dos Pólos Indígenas.

Para obtenção do material empírico optou-se pela técnica de grupo focal. Foram organizados três grupos focais, estabelecidos segundo a disponibilidade dos profissionais em participar da pesquisa. A composição dos grupos foi planejada de modo a serem homogêneos e funcionais, com no mínimo quatro e máximo de doze participantes cada ${ }^{(10)}$. Os profissionais foram convidados para reunião em data e horários previamente agendados, em concordância com o parecer de cada coordenação local, evitando qualquer prejuízo no andamento do trabalho das equipes de saúde.

Antes de iniciar a pesquisa os participantes assinaram o Termo de Consentimento Livre e Esclarecido (TCLE), elucidando de forma clara e sucinta os objetivos do estudo. Ressalta-se, ainda, que dentre as categorias profissionais participantes da pesquisa, apenas os AIS pertenciam a etnia indígena Potiguara. Logo, formulou-se um termo de consentimento específico para esse grupo, além daquele dirigido às outras categorias.

O primeiro grupo focal foi realizado no município de Rio Tinto e reuniu sete profissionais de saúde. Na sequência, foram realizados os encontros com as equipes de Marcação e Baía da Traição, envolvendo respectivamente cinco e onze participantes.

Utilizou-se um roteiro, contendo uma lista de temas que serviu de guia para o moderador, facilitando a coordenação do trabalho grupal. $O$ instrumento norteador da discussão partiu de uma ficha de identificação das ações de controle da TB, distribuídas no início do encontro. Esse instrumento requereu dos participantes elegerem cinco situações envolvendo ações das equipes, no cuidado ao usuário com TB, tendo como foco os recursos estruturais disponíveis e organização do serviço. Além da presença do moderador, contou-se com a presença de dois assistentes - relatores-observadoresque observaram a conduta do grupo e registraram as informações verbais e não-verbais que emergiram durante o encontro. Os depoimentos foram gravados conforme autorização concedida pelos participantes.

A categorização dos depoimentos foi realizada mediante a técnica da análise do discurso ${ }^{(11)}$ e obedeceu às seguintes etapas: transcrição dos depoimentos na íntegra, impressão e leitura dos textos, identificação dos temas relacionados ao objeto e objetivos do estudo; recorte, decomposição dos textos que apresentem temas recorrentes pelos diferentes sujeitos da investigação; agrupamento dos textos que se refiram aos temas coincidentes, permitindo a formação de blocos de significados, os quais orientaram a construção da categoria empírica "Organização do serviço de controle da TB: contradições na prática das equipes de saúde indígena".

Os participantes foram decodificados com letras e números, de forma a garantir seu anonimato, bem como atender os aspectos éticos e legais da pesquisa envolvendo seres humanos, preconizados pela Resolução 
No 196/96 do Conselho Nacional de Saúde, além das determinações da Resolução 304/2000, no que diz respeito à temática especial "populações indígenas"(12). 0 projeto que deu origem a este trabalho foi aprovado pelo Comitê de Ética em Pesquisa do Centro de Ciências da Saúde, da Universidade Federal da Paraíba em 28 de fevereiro de 2007, sob Protocolo ${ }^{\circ}$ 0891/07.

\section{RESULTADOS}

\section{Organização do serviço de controle da TB:} contradições na prática das equipes de saúde indígena

A descoberta precoce dos casos de TB, por meio da busca ativa de sintomáticos respiratórios (SR) na comunidade, constitui-se em importante atribuição das equipes de saúde. A busca de casos consiste em descobrir fontes de infecção (casos bacilíferos), identificando pessoas que apresentam tosse e expectoração por três semanas ou mais. Contudo, viabilizar tal atividade requer um acompanhamento constante por parte das equipes e uma atuação planejada e comprometida com a continuidade da atenção iniciada ${ }^{(13)}$.

No tocante à execução dessas ações no âmbito do DSEI Potiguara, evidencia-se que o modo de organização hierárquica na definição de estratégias de identificação de casos na comunidade não se consolida em atenção continuada na prática das equipes indígenas:

[...] Faz uns seis meses que [a coordenadora da Epidemiologia] ela deu uma lista pra gente [...] entrevistar as famílias e saber se eles têm uns sinais, uns sintomas que podem ser tuberculose [...] não deu pra concluir a aldeia toda, conclui só a metade! (C9).

No fragmento discursivo supracitado é marcante a improvisação da equipe na busca de casos na comunidade, revelada não como uma rotina do serviço, mas como um modelo de atuação burocrática, mobilizada pelo Setor de Vigilância Epidemiológica. Esse serviço, enquanto parte da rede de apoio do Programa de Controle da Tuberculose, deveria, juntamente com a coordenação do Pólo Indígena local, planejar e qualificar a condução dos trabalhos para evitar que a busca de casos na comunidade fosse realizada de forma isolada e descontinuada ${ }^{(14)}$.

Os achados revelam ainda que a programação centralizada na figura do profissional da vigilância retrata uma linha de comando e de gestão vertical que induz a fragmentação do cuidado:

A enfermeira da Epidemiologia orientou que, no caso de tosse persistente, febre [...] poderiamos solicitar duas amostras de escarro e avisar no pólo para o motorista pegar no dia seguinte (C4);

[...] a gente já deixou formulários nas casas e eles [usuários] ligavam para o pólo avisando, aí a gente ia lá, entregava os potinhos e no outro dia, avisava ao motorista pra ir pegar (C4);

[A responsabilidade] é do próprio paciente! Que faz o escarro e o motorista pega na casa dele e leva pra lá pra o laboratório! (C4).

Nos depoimentos em análise, constata-se que a responsabilidade dos profissionais da equipe se resume à entrega dos respectivos formulários e dos potes para a coleta de escarro, cabendo ao usuário a responsabilidade pela qualidade do material coletado e ao motorista o recolhimento e transporte ao laboratório.

Quanto ao suprimento e oferta de insumos para coleta de escarro, observa-se nos discursos que embora em algumas aldeias mais distantes as equipes tenham de recorrer a improvisação, a maioria conta com a disponibilidade de recipientes:

Tem [pote]. Se precisar hoje tem! (C3);

Já faltou! [...] Mas agora sempre tem! (C6);

[...] no meu caso, eu não tenho potinho, eu implemento um pote e ele faz [o exame] aqui [no posto] [...]. (C9);

Manda pegar um vidrinho, escaldar [...]. (C4).

A baciloscopia é um exame de rápido resultado diagnóstico e na rotina do DSEI Potiguara os depoimentos são unânimes quanto à agilidade de tal procedimento:

Em média 48 horas já dá o resultado! (C3);

É rápido [...] No outro dia, já dá o resultado. (C5).

Em contrapartida, o próximo relato vem acrescentar que a referida rapidez na entrega do resultado está condicionada à determinadas situações:

Quando é um caso suspeito, ai é rápido! [...] Não passa de uma semana! (C4). 
Especificamente no DSEI Potiguara, a rede laboratorial encontra-se localizada no município da Baía da Traição, presumindo a necessidade de um veículo para o transporte das amostras advindas dos municípios de Marcação e Rio Tinto em tempo hábil. Nesse contexto, nos próximos relatos podem ser percebidas que a questão do transporte é um importante componente incorporado às ações de controle da TB dentro da realidade dessas equipes:

[...] o médico solicita ou até mesmo a enfermagem solicita a baciloscopia, duas amostras, é seguida de imediato para a Baía, até que consiga transporte [...] isso ai é uma dificuldade na nossa realidade, em se tratando de paciente com tuberculose aí não passa a ser. Porque de imediato arruma! (C3).

Embora o transporte sanitário caracterize-se como importante desafio para os sistemas logísticos, a disponibilização de viaturas não constitui um problema concernente ao envio das amostras do material para análise bacteriológica:

Com relação a transporte na maioria das vezes tem! (C1).

A disponibilidade do transporte se estende também para ocorrências que, por ventura, venham a ocorrer na aldeia, bastando apenas um contato prévio:

[...] por mais que nós tenhamos problema com veículo, [o paciente] entrando em contato pelo menos com o AIS, que liga pra cá e a gente disponibiliza o carro pra pegar esse paciente. 0 paciente que precisar, com certeza, a gente ou uma ambulância de emergência se for o caso, e até mesmo a Toyota que leva a equipe pra aldeia, se encarrega de ir pegar esse paciente. Pelo menos nesse aspecto realmente é eficaz!(C6).

Notadamente, problemas de acessibilidade geográfica são frequentemente relatados entre os participantes desta pesquisa, como situação de rotina no trabalho das equipes de saúde indígena Potiguara, em razão da distância existente entre as aldeias e os PólosBase, localizados em municípios-sede. O depoimento seguinte corrobora com tal afirmação:
Tem uns [pacientes] que vêm a pé, de longe [...] às vezes precisa vir de carro, aí às vezes paga [...] e caro!(C4).

Contudo, a disponibilidade do transporte para o usuário indígena é identificada como facilitada quando a situação de saúde exige encaminhamento aos serviços de referência em outros municípios:

Ela [a médica] faz um encaminhamento no receituário [...] a historinha do paciente e chama a ambulância (C4);

[...] eles são encaminhados sem nenhum problema [...] tem transporte (C2);

No caso da minha paciente vinha um rapaz da FUNASA na Toyota e levava. (C9).

Embora as ações de controle da TB, exijam para o seu manejo diagnóstico e clínico, ações de baixa densidade tecnológica, eventualmente os serviços especializados e/ou de referência são acionados pelas equipes da atenção básica, seja para elucidação de formas clínicas extra-pulmonares ou investigação radiológica:

[...] é possivel encaminhar esse paciente para João Pessoa, para fazer Raio $X$ de tórax [...] depois faz seguimento, aqui [...]. (C3);

quando exame de escarro é negativo é solicitado o Raio $X$ que é feito em João Pessoa e muitas vezes demora. (C4).

A deficiência estrutural da rede local para exames de tal magnitude, culmina com diversas dificuldades na rotina do serviço, haja vista a necessidade de deslocar o paciente para outro município, disponibilizar transporte, ocorrência de atrasos para a divulgação dos resultados, entre outras situações referidas que resultam em perda de tempo e ônus para o Sistema de Saúde.

Contudo, é válido ressaltar que diante de casos de difícil manejo terapêutico em razão de multiresistência ou de reações adversas aos medicamentos, faz-se necessário que o paciente seja tratado e acompanhado nas unidades de referência. Logo, uma das atribuições da equipe nesse processo é o acompanhamento da evolução dos casos:

A gente fica tentando saber notícias! Tentando porque a gente nem tem muito tempo. A gente às vezes liga! Quando 
a gente chega no Pólo, já é pra ir pra aldeia de manhã cedo, quando volta já é hora de ir embora. Mas muitas vezes a gente liga para o hospital ou para assistente social para saber. Muitas vezes a gente vai na casa dele para conversar com a esposa, com a família [...]. (C4);

[...] mesmo ele estando em referência, ia ver esses comunicantes, não só solicitar os exames e também acompanhar na medida do possivel, o que está acontecendo a nivel de referência. (C3).

Identifica-se nos fragmentos citados que os profissionais de saúde indígena realizam o acompanhamento dos casos que se encontram em tratamento na referência, seja por meio do contato com a família ou pela busca incessante de informações na unidade de referencia estadual, que muitas vezes é dificultada pela falta de tempo disponível, durante a rotina diária desses profissionais.

Observa-se, ainda, dificiência na conformação de uma rede integrada e horizontalizada, cujo acesso à informação é dificultada entre os diferentes pontos do sistema:

O serviço não dá contra-referência pra nós! [...] a [dificuldade] é da contra-referência só porque quando é encaminhamento não tem problema. (C1);

[...] [informação] só quando eu vou atrás, quando a gente procura porque o serviço de lá não te manda a contra referência [...] (C2).

Diante de tais relatos, apresenta-se a extensão dos desafios da coordenação em promover compartilhamento de informações a respeito de pacientes e ações geradas em diferentes níveis do sistema. Por conseguinte, cabe ao gestor e as equipes locais criar dispositivos operacionais que atendam às necessidades da população. Os serviços devem ser prestados oportunamente e em caráter contínuo, bem como estar disponíveis a qualquer momento, atender à demanda real e incluir um sistema de referência que assegure fácil acesso ao nível de assistência que se requer.

\section{DISCUSSÃO}

Na literatura, a busca ativa de SR representa uma ação que transcende o saber biológico(13-15), à medida que necessita de uma abordagem complexa que vai desde o contato no domicílio, a orientação sobre a doença, sinais e sintomas, modo de transmissão, identificação do SR, orientação sobre a coleta do escarro, encaminhamento e recebimento do material pela UBS, fluxo de exame ao laboratório de análise, recebimento do resultado pela unidade e usuário, até o encaminhamento para o seguimento ambulatorial dos casos diagnosticados.

Tanto a escassez de insumos quanto a não sistematização das atividades relacionadas à busca ativa de SR, traz como resultado uma atuação comprometida com a continuidade da atenção iniciada e a eficácia dos resultados e, portanto, havendo dificuldades na identificação de casos de TB na população potiguara, situação esta que pode subdimensionar a frequência da tuberculose neste cenário(6).

Estudo realizado em Ribeirão Preto(13) assinala os dados apresentados em relação a inviabilidade de transporte, mostra que dos 81 Agentes Comunitários de Saúde, 22\% mencionaram dificuldades para proceder o encaminhamento do material coletado para o laboratório em virtude da falta de transporte. Essa situação pode ser explicada em função do contexto desfavorável onde paira o difícil acesso aos recursos diagnósticos localizados nos municípios vizinhos, que atuam como serviços de referência.

No que diz respeito à organização, funcionamento e facilidade do acesso ao diagnóstico de TB no DSEI Potiguara, ressaltam-se os problemas de acessibilidade geográfica dos laboratórios em razão da distância existente entre as aldeias e os serviços diagnósticos, localizados em outros municípios.

Embora esteja prescrito como princípio básico da atenção básica que as equipes atuem em território, com área de abrangência adstrita, deve-se considerar que os municípios são heterogêneos, com áreas de difícil acesso e realidades geográficas diferenciadas. Portanto, a acessibilidade geográfica é medida pela distância entre a população e os recursos, tempo de deslocamento e custo do transporte ${ }^{(16)}$. Quando se dispõe de serviços descentralizados, e mais próximos à população, o deslocamento é facilitado.

A problemática do transporte sanitário é um obstáculo do sistema de saúde indígena e o DSEI Potiguara mostra algumas peculiaridades que potencializam essa questão, à medida que o transporte é 
um componente incorporado às ações de controle da TB neste cenário. Tal fato contraria estudos realizados em outros cenários indígenas que tomam como objeto de análise os entraves da organização do serviço de saúde indígena(17)

Quanto ao fluxo de informações entre os serviços que compõem a rede de cuidados aos doentes de TB, evidenciou-se particularmente que esta dificuldade centra-se nas unidades periféricas, comprometendo a continuidade da assistência ${ }^{(16)}$. Considerando as debilidades deste mecanismo no DSEI Potiguara, se faz necessário aprimoramento do mesmo.

Designar o manejo continuado que permita um cuidado centrado no doente de TB ao longo do tempo e em vários pontos de atenção, ora investigado como prática inerente à articulação da coordenação do Programa de Controle da Tuberculose (PCT) dentro de um sistema integrado de serviços, reflete realidade passível de discussão em outros cenários de estudo(18). Assim, torna-se explícita a responsabilização da coordenação do PCT local no compartilhamento de informações e no estabelecimento de providências que promovam a redução das lacunas inerentes à lógica dos sistemas fragmentados expressos nessa pesquisa.

Essa fragmentação foi identificada dentro da organização das ações de controle da TB do DSEI Potiguara pela estruturação da rede de serviços pautada em níveis crescentes de complexidade tecnológica, que se configuram, na maioria dos casos, como um conjunto de pontos de atenção isolados e incomunicáveis entre si, incapaz de prestar uma atenção continuada às pessoas e de se responsabilizar por uma população determinada, debilidade igualmente evidenciada em outros municípios $^{(13,19)}$.

As atividades de controle da TB que se organizam no sistema de saúde de forma descentralizada, incluem aquelas de natureza técnica como as ações de busca de SR e acompanhamento dos casos, realizadas nos serviços mais periféricos do sistema de saúde através de uma equipe generalista. Por outro lado, atividades gerenciais incluindo planejamento terapêutico, notificação compulsória, sistema de informação, planejamento de insumos e medicação, monitoramento e avaliação se organizam no sistema de saúde de forma centralizada, através da coordenação do $P C T^{(20)}$.

Para tanto, atribui-se a essa coordenação a negociação constante com os diversos níveis para inserir a TB como prioridade de saúde no município, bem como estimular o envolvimento das equipes para a incorporação das ações de TB em nível local. Nesses termos, a execução das atividades gerenciais pela coordenação do PCT presume uma atuação profissional com habilidade gerencial e conhecimentos técnicos para efetivar o planejamento das ações, além do treinamento, supervisão e monitoramento das equipes locais que executam as atividades de controle da $\mathrm{TB}^{(14)}$.

Os desafios para a viabilização das ações de controle da TB no DSEI Potiguara incluem, além do avanço na organização de um sistema integrado de saúde que contemple a articulação permanente dos responsáveis pelo controle da doença nos diversos níveis do sistema, a adoção de estratégias que fortaleçam a capacidade gerencial da coordenação local e resultem num cuidado coordenado para a superação das fragilidades por hora apresentadas.

\section{CONCLUSÃO}

A partir da análise da organização do serviço de controle da TB no DSEI Potiguara, pôde-se observar que as ações estão centradas no setor de Vigilância Epidemiológica, retratando uma linha de comando e gestão vertical que induzem à fragmentação do processo de trabalho. Ressalta-se, ainda, a insuficiência e descontinuidade de fluxo de material para identificar os casos. Quanto a esta perspectiva diagnóstica, a equipe de saúde se limitou apenas à entrega do insumo para coleta de escarro e o preenchimento do formulário do exame bacteriológico, sem, contudo, haver uma orientação a respeito de como deveria ser feito corretamente o procedimento para a aquisição de uma amostra adequada.

Somando-se a essas debilidades, a distância entre a rede laboratorial e os serviços de saúde na região, a deficiência no fluxo de informações entre os diferentes pontos da rede de atenção, configuram-se em limitações para a promoção de um cuidado articulado e contínuo dentro do sistema de saúde público.

Neste aspecto, a coordenação, enquanto princípio ordenador de fluxo de trabalho, passa a ocupar um dos elementos-chave para assegurar a eficiência desse processo organizativo, buscando superar os problemas relacionados à implementação do PCT na esfera local. 
Constatou-se que a deficiência de tal dispositivo dentro do serviço de TB do DSEI Potiguara configura-se entre as limitações identificadas, existindo uma desorganização para articular as ações desenvolvidas pelas equipes, revelando um serviço dependente da

\section{REFERÊNCIAS}

1. Barreira D. Antigo e atual problema de saúde pública. Radis. 2011;(106):20-1.

2. Marques AMC, Pompilio MA, Santos SC, Garnês SJA, Cunha RV. Tuberculose em indígenas menores de 15 anos, no Estado de Mato Grosso do Sul. Rev Soc Bras Med Trop. 2010;43(6):70004.

3. Machado Filho AC. Incidência da tuberculose em indígenas do município de São Gabriel da Cachoeira, AM. Rev Soc Bras Med Trop. 2008;41(3):243-46.

4. Bóia MN, Carvalho-Costa FA, Sodré FC, Porras-Pedroza BE, Faria EC, Magalhães GAP, et al. Tuberculose e parasitismo intestinal em população indígena na Amazônia brasileira. Rev Saude Publica. 2009;43(1):176-8.

5. Melo TEMP, Resendes APC, Souza-Santos R, Basta PC. Spatial and temporal distribution of tuberculosis in indigenous and non-indigenous of Rondônia State, Western Amazon, Brazil. Cad Saude Publica. 2012;28(2):267-80.

6. Nóbrega RG, Nogueira JA, Ruffino-Netto A, Sá LD, Silva ATMC, Villa TCS. A busca ativa de sintomáticos respiratórios para o controle da tuberculose, no cenário indígena potiguara, Paraíba, Brasil. Rev Lat Am Enfermagem. 2010;18(6):1169-76. 7. Ogden J, Walt G, Lush L. The politics of branding in policy transfer: the case of DOTS for tuberculosis control. Soc Sci Med. 2003;57(1):179-88.

8. Hartz ZM, Contrandriopoulos, AP. Integralidade da atenção e integração dos serviços de saúde: desafios para avaliar a implantação de um "sistema sem muros". Cad Saúde Publica. 2004; 10 Suppl 2:S331-6.

9. Merhy EE, Cecílio LCO. O singular processo de coordenação dos hospitais. Rev Saúde em Debate. 2003;27(64):110-122. 10. Mazza VA, Melo NSFO, Chiesa, AM. O grupo focal como técnica de coleta de dados na pesquisa qualitativa: relato de experiência. Cogitare Enferm. 2009;14(1):183-8.

11. Fiorin JL. Elementos de Análise do Discurso. 13. ed. São Paulo: Contexto; 2005.

12. Conselho Nacional de Saúde, Ministério da Saúde.

Resolução No 304/2000 - Diretrizes e normas regulamentadoras de pesquisa envolvendo populações indígenas. Brasília (Brasil): Ministério da Saúde; 2000.

13. Nogueira JA, Ruffino A Netto, Monroe AA, Gonzales RIC, Villa TCS. Busca ativa de sintomáticos respiratórios no controle da tuberculose na percepção do agente de saúde. Rev. Eletr. Enf. [internet] 2007. [cited 2011 nov 10]; 9(1):106-18. Available from: http://www.fen.ufg.br/revista/v9/n1/v9n1a08.htm 14. Muniz JN, Palha PF, Monroe AA, Gonzales RC, Ruffino Netto A, Villa TCS. A incorporação da busca ativa de sintomáticos respiratórios para o controle da tuberculose na prática dos agentes comunitários. Cien Saude Colet. 2005;10(2):315-21. 15. Silva CC, Silva ATMC, Losing A. A integração e articulação entre as ações de saúde e de educação no Programa de Saúde da Família - PSF. Rev. Eletr. Enf. [internet] 2006; [cited 2011 nov 10]; 8(1):70-4. Available from:

http://www.fen.ufg.br/revista/revista8 1/original 09.htm 16. Starfield B. Atenção Primária: equilíbrio entre necessidades de saúde, serviços e tecnologia. Brasília: Ministério da Saúde; 2002. capacidade de processar informação e assegurar um processo decisório compartilhado. Portanto, é urgente repensar a prática desses serviços no DSEl Potiguara, permitindo a continuidade do cuidado na perspectiva de garantir atenção integral ao doente de TB.

17. Chaves MBG, Cardoso AM, Almeida C. Implementação da política de saúde indígena no Pólo-base Angra dos Reis, Rio de Janeiro, Brasil: entraves e perspectivas. Cad Saude Publica. 2006;22(2):295-305.

18. Assis EG, Beraldo AA, Monroe AA, Scatena LM, CardozoGonzales RI, Palha PF, et al. A coordenação da assistência no controle da tuberculose. Rev Esc Enferm USP. 2012; 46(1):111-8 19. Monroe AA, Gonzales RIC, Palha PF, Sassaki CM, Ruffino Netto A, Vendramini SHF, Villa TCS. Envolvimento de equipes da Atenção Básica à Saúde no Controle da Tuberculose. Rev Esc Enferm USP. 2008;42(2):262-7.

20. Villa TCS, Ruffino-Netto A, Arcêncio RA, Cardozo-Gonzales RI. As Políticas de Controle da Tuberculose no Sistema de Saúde no Brasil e a implantação da Estratégia DOTS (1980-2005). In: Ruffino-Netto A, Villa TCS. A implantação do DOTS em algumas regiões do Brasil:histórico e peculiaridades regionais. Ribeirão Preto: Instituto Milênio/Rede TB; 2006. p. 29-47.

Artigo recebido em 14/11/2011

Aprovado para publicação em 13/08/2012.

Artigo publicado em 31/03/2013. 